\title{
SIMPLE BONE CYST TREATED WITH PERCUTANEOUS STEROID INJECTION
}

\author{
ACHMAD FAUZI KAMAL, AJIANTORO*, YOGI PRABOWO
}

Department of Orthopaedic and Traumatology, Cipto Mangunkusumo General Hospital, Faculty of Medicine University of Indonesia, Indonesia. Email: ajiantoro99@gmail.com

Received: 03 August 2017, Revised and Accepted: 18 January 2018

\section{ABSTRACT}

Objectives: Through this study, we want to explore the effectiveness of methylprednisolone injections to treat simple bone cyst (SBC).

Methods: We collected the data of all patients with SBC that were treated with percutaneous steroid injection (PSI). The study was conducted in Cipto Mangunkusumo Hospital and we used a computerized search of operative reports to identify all SBC patients who were treated by PSI 3 times between 2013 and 2016.

Results: A total of 10 patients were reported in these serial cases, 8 males and 2 females. The average age of these subjects is 7.8 years old. Musculoskeletal Tumor Society functional score determine good result after $3^{\text {rd }}$ injection of steroid. Bone healing evaluation using Chang Criteria showed a good healing proccess.

Conclusion: Steroid injection therapy for SBC yielded a good functional result. It gets solid union relatively quickly, simple operation procedure, widely available, with less side effect. Therefore, this procedure could be a choice for treatment of SBCs patient. Further study needs to be conducted with more sample size.

Keywords: Simple bone cyst, Steroid injection, Bone healing.

(C) 2018 The Authors. Published by Innovare Academic Sciences Pvt Ltd. This is an open access article under the CC BY license (http://creativecommons. org/licenses/by/4. 0/) DOI: http://dx.doi.org/10.22159/ajpcr.2018.v11i5.21775

\section{INTRODUCTION}

Simple bone cyst (SBC) is a benign tumor that is relatively rare. It usually occurs in the first and second decade of life. The symptoms of SBCs include pain, swelling, or stiffness at the nearest joint. A pathologic fracture is often the first sign of the lesion that patient realizes [1]. The expansive cysts tend to thin and weaken the involving bone, producing a mechanical threat that may result in subsequent pathological fracture. The etiology is unknown, but it is suspected that venous obstruction elevates intraosseous pressure, leading to cyst formation [2]. Other theories proposed include nitric oxide [3], increased lysosomal enzyme activity [4], prostaglandins [5], oxygen free radicals [6], disorders of synovial origin [7], and genetic causes [8].

Radiographically, the appearance of the SBC is centrally located, wellcircumscribed, radiolucent lesion with sclerotic margins. The lesion is located within the diaphysis or the metaphysis of a long bone, abutting or being remote from the cartilaginous growth plate, and epiphyseal extension is unusual. The cortex is frequently thinned, and cortical expansion may be present, but the width of the SBC does not exceed the width of the neighboring plate. A periosteal reaction is absent unless there has been a pathologic fracture. The diagnosis may be demonstrated by conventional radiographs and magnetic resonance imaging (MRI) [1].

The purpose of treatment of SBC is to restore bone strength, cortical thickness, and obliteration of the cyst, as well as to prevent all possible complications, and prolonged restriction of physical activity $[1,9,10]$. The appropriate treatment, however, remains uncertain, and a wide spectrum of treatment modalities have been proposed ranging from observation to subtotal resection [1].

More than 20 methods of treating SBCs have been described in the literature, the most commonly used ones being curettage and bone grafting, autogenic bone marrow, flexible intramedullary nailing, and injections of steroids. Decompression and percutaneous steroid injection (PSI) has many advantages, such as its simplicity, low cost, high availability, and lack of direct post-operative adverse effects [9]. A study published by Scaglietti et al. reported that methylprednisolone injections into the cyst resulted in a 96\% treatment success rate [11]. This study reports the results of patients who were treated by steroid injections in our institution.

\section{METHODS}

We collected the data of all SBC patients who were treated with three times PSI in Cipto Mangunkusumo Hospital between 2013 and 2016. The diagnosis of SBC was established by means of radiographs and MRI, while functional outcomes were measured by Musculoskeletal Tumor Society (MSTS) score. Lastly, post-PSI evaluation was conducted based on radiographic examinations using Chang criteria 1 month after each injection (Fig. 1).

The MSTS Scoring system is divided into 4 categories, with the maximum score being 30 ; the score $<25 \%$ of maximal score is categorized as bad, $25-49 \%$ is categorized as fair, $50-74 \%$ is categorized as good, and $>75 \%$ is categorized as very good.

The PSI in our hospital was performed with the following procedure:

- With the patient under general anesthesia, we visualize the lesion with $\mathrm{C}$-arm guidance

- Core bone needles no 11 are introduced in the proximal and the distal pole of the cystic lesion

- We evaluate the fluid (color) which came out from the cavity without force and send it to histopathologic examination

- After the characteristic fluid of SBC is empty, we aspirate hemorrhagic one from the cavity and also send it to histopathologic examination

- The cavity was flushed with normal saline from proximal core bone needle,

- With closed distal core bone needle, we perform PSI 80-120 mg. 


\section{RESULTS}

This study includes 10 patients consisting of 8 males and 2 females, with the mean age of 7.8 years old (range 3-14 years old). The mean follow-up was 12.6 months (range 5 - 48 months). The locations of SBC in these patients are as follows; 6 cases located at the humerus, 3 cases located at the femur, and remaining 1 case located at the calcaneus. Four of these patients were presented with pathological fractures. We followed up each patient every 1 month until 3rd PSI was completed, and every 6 months thereafter. The overall characteristic features of the patients are shown in Table 1

Successful clinical outcomes with very good MSTS score were observed 90 of $10(90 \%)$ and all cases $100 \%$ in 3 and 6 months after $3^{\text {rd }}$ PSI,

Table 1: Demographic characteristics of the patients

\begin{tabular}{lc}
\hline Characteristic & $\mathbf{N = 1 0 ( \% )}$ \\
\hline Age (mean \pm SD) & $7.8 \pm 1.2$ y \\
Group age & $7(70)$ \\
$0-10$ y & $3(30)$ \\
$11-20$ y & \\
Sex & $8(80)$ \\
Male & $2(20)$ \\
Female & \\
Location & $6(60)$ \\
Humerus & $3(30)$ \\
Femur & $1(10)$ \\
Calcaneus & \\
Site & $3(30)$ \\
Right & $7(70)$ \\
Left & \\
Pathological fracture & $4(40)$ \\
Yes & $6(60)$ \\
No & \\
\hline Results were described in frequency (percentage) for proportion data and \\
mean \pm SD for numerical data; N=number of patients, y=year. SD: Standard \\
deviation
\end{tabular}

Table 2: MSTS functional score in SBC patients

\begin{tabular}{|c|c|}
\hline Variable & MSTS score n (\%) \\
\hline \multicolumn{2}{|c|}{ Time of evaluation pre-procedure } \\
\hline Bad & $3(30)$ \\
\hline Fair & $7(70)$ \\
\hline Good & $0(0)$ \\
\hline Very good & $0(0)$ \\
\hline \multicolumn{2}{|c|}{1 month after $1^{\text {st }}$ PSI } \\
\hline Bad & $0(0)$ \\
\hline Fair & $3(30)$ \\
\hline Good & 7 (70) \\
\hline Very good & $0(0)$ \\
\hline \multicolumn{2}{|c|}{1 month after $2^{\text {nd }}$ PSI } \\
\hline Bad & $0(0)$ \\
\hline Fair & $0(0)$ \\
\hline Good & $5(50)$ \\
\hline Very good & $5(50)$ \\
\hline \multicolumn{2}{|c|}{1 month after $3^{\text {rd }}$ PSI } \\
\hline Bad & $0(0)$ \\
\hline Fair & $0(0)$ \\
\hline Good & $3(30)$ \\
\hline Very good & $7(70)$ \\
\hline \multicolumn{2}{|c|}{3 month after $3^{\text {rd }}$ PSI } \\
\hline Bad & $0(0)$ \\
\hline Fair & $0(0)$ \\
\hline Good & $1(10)$ \\
\hline Very good & $9(90)$ \\
\hline \multicolumn{2}{|c|}{6 month after $3^{\text {rd }}$ PSI } \\
\hline Bad & $0(0)$ \\
\hline Fair & $0(0)$ \\
\hline Good & $0(0)$ \\
\hline Very good & $10(100)$ \\
\hline
\end{tabular}

Results were described in frequency (percentage) for proportion data; $\mathrm{n}=$ number of patients. MSTS: Musculoskeletal Tumor Society, SBC: Simple bone cyst, PSI: Percutaneous steroid injection respectively. MSTS scoring evaluation of this study is presented in Table 2.

We noted no recurrent cases or no response to treatment in our study during follow-up. Bone healing was assessed using Chang criteria for radiological examination (Fig. 2)

We also recorded size of lesion after patients got complete PSI (Fig. 3), of which the smallest size of lesion was $0,2 \mathrm{~cm}$ and the largest was $1 \mathrm{~cm}$.

\section{DISCUSSION}

Many studies stated that SBC is more common in males than in females with comparison 3:1 and it particularly occurred in the first and second decades of life. The most common predilection of SBC is in proximal humerus (59\%) followed by proximal femur $(25 \%)$ and calcaneus $(6 \%)[1,12]$. The result of this study follows the trend of previous studies with the prevalence of SBC more common in males than in females (8:2). Also similar with previous studies, SBCs in our cases occurred on the first and second decades of life with 6 of $10(60 \%)$ cases located in the humerus, followed by 3 of $10(30 \%)$ in the femur and the remaining $1(10 \%)$ in the calcaneus.

In our study, pathological fractures were significantly more common in the humerus than femur which was comparable to previous studies. It is believed that due to the absence of a significant mechanical load, which usually leads to significant pain, SBC in the humerus remains undetected longer than femur. Thus, SBCs in the humerus often grow until they reveal themselves through a pathological fracture usually arising in the context of a minimal trauma [13].

The appropriate treatment, however, remains uncertain, with a wide spectrum of treatment modalities having been proposed ranging from observation to subtotal resection. The most common of which being the Intralesional curettage combined with bone graft or synthetic graft $[14,15]$. It was also the standard treatment in all SBC patients in our hospital before 2013. Curettage eradicates the source of bonedestroying enzymes by cleaning the cyst membrane and bone/synthetic graft acts as an osteoconductive for bone healing process [13,14]. SBCs were initially treated with curettage and bone grafting, but the recurrence rate was $40-60 \%[15,16]$.

The role of methylprednisolone in enhancing bone healing is by reducing the cyst fluid production from the inner cyst wall with its antiprostaglandin effect or by decreasing the cyst pressure after initially drilling a hole and aspirating the fluid [17]

The fluid of SBC contains combination of substances, including are prostaglandins, free oxygen radical, interleukins, cytokines and metalloproteinase. This combination of substances results in higher pressure of the fluid inside the cyst compared to pressure in the bone marrow causing bone necrosis. Some of the SBC will spontaneously recover, however others may also enlarge until symptoms exist and requiring treatment $[10,14,18]$.

From many of previous studies, the efficacy of PSI in SBC patients is still debatable. Study conducted by Kadhim et al. stated that the curettage therapy has higher rate bone healing compared to steroid therapy (98.7\% vs $77.4 \%$ ) [12]. Meanwhile, Mylle et al. mentioned in their study that steroid is a chosen method for treatment of SBC due to it is simplicity, effectiveness and safety [14]. Scaglietti et al. reported that methylprednisolone injections into the cyst resulted in a $96 \%$ treatment success rate [11]. In our study, PSI resulted in good response and no recurrent cases during follow up.

All patients were treated with 3 times of PSI with 1 month interval for each injection. The number of injection referred from several previous studies. Campanacci et al. reported healings in $68 \%$ of cysts treated with methylprednisolone [19]. Each patient was submitted to 3-4 
injections of methylprednisolone. Hashemi-Nejad et al. also performed a similar study that a number of injections was 3 times [20]. Moreover, a study from Scaglietti et al. noticed that $76 \%$ of failure happened in one-time PSI treatment [11].

The patient's functional outcomes were evaluated using MSTS scoring system which is divided into upper and lower extremity. Each item has 0-5 scale, with higher score reflects higher progression of functional outcomes. The results show that 6 months after 3rd PSI, functional outcomes of all patients are very good even exceeding several previous studies. A study from Cho et al. found the success rate after steroid injection for SBC was $86.7 \%$ (26 of 30 patients) [21]. Another study that was conducted by Pavone et al. showed a good clinical outcome after steroid injection (98/100) [22].
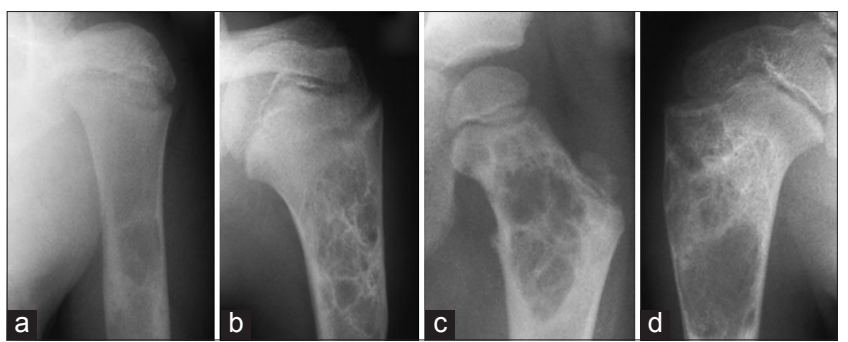

Fig. 1: Radiographic evaluation by Chang criteria. (a) Healed cyst (b) healing with defect, (c) persistent cyst, (d) recurrent cyst
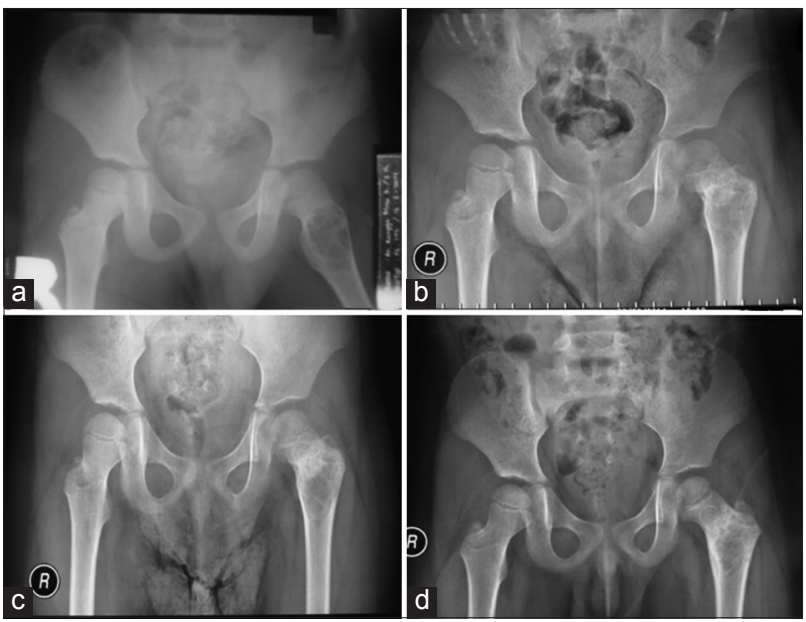

Fig. 2: Radiology evaluation in patient with simple bone cyst on left femur. (a) pre-injection (b) 1 -month post $1^{\text {st }}$ injection (c) 1-month post $2^{\text {nd }}$ injection (d) 1-month post $3^{\text {rd }}$ injection

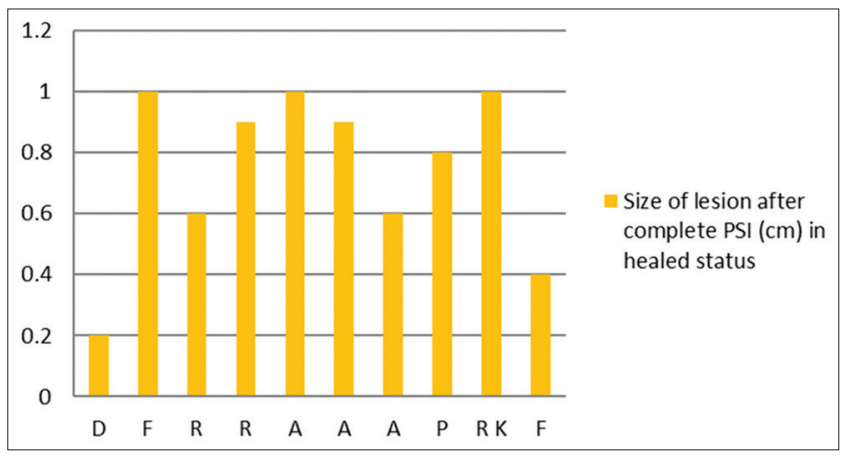

Fig. 3: Size of lesion evaluation after complete percutaneous steroid injection (PSI) in patient with a simple bone cyst on left femur. After PSI, the radiographic evaluation of all patients by Chang criteria achieved healed criteria
The radiographic outcomes were measured using Chang criteria [23]. Based on this criteria, there are 4 classifications of bone healing, those are (1) healed (cyst filled by formation of new bone with or without small static, radiolucent area(s) $<1 \mathrm{~cm}$ in size), (2) healed with defect (static, radiolucent area(s) less than $50 \%$ of the diameter of bone with enough cortical thickness to prevent fracture), (3) persistent cyst (radiolucent areas $>50 \%$ of diameter of the bone and with a thin cortical rim. No increase in cyst size. Continued restriction of activity or repeated treatment is required), and (4) recurrent cyst (cyst reappeared in a previously obliterated area or a residual radiolucent area has increased in size). Radiographic examination was performed before first injection, as well as 1 month after $1^{\text {st }}, 2^{\text {nd }}$, and $3^{\text {rd }}$ PSI, respectively.

The results shows that all patients have good radiological outcomes (complete healing) in 6-month follow-up after $3^{\text {rd }}$ injection. All of the patients were healed (cyst filled by the formation of new bone with or without small static, radiolucent area(s) $<1 \mathrm{~cm}$ in size). These results are better from several previous studies. Oppenheim et al. conducted a study to evaluate steroid injection in SBC, and the result was $75 \%$ of the cysts which achieved satisfactory radiological healing after numerous injections [24]. A meta-analysis study from Kadhim et al. published that radiological healing after steroid injection for SBCs achieved $83.6 \%$ [12].

In our cases, clinical outcomes were consistent with radiological outcomes. Other case series also showed satisfactory radiological and clinical outcomes following steroid injection [25]. Hashemi-Nejad et al. reported 24 of $24(100 \%)$ children with satisfactory radiological outcomes and 23 of 24 (96\%) had good clinical results. However, 5 of $8(63 \%)$ children with an unsatisfactory radiological outcome had a satisfactory clinical result. Hashemi-Nejad reported that good radiological outcomes always had good clinical outcomes, but good clinical outcomes are not always in line with good radiological outcomes [20].

The relationship between basic characteristics with bone healing and SBC recurrence from several previous studies remains controversial. Chang et al. confirmed that there is a significant relationship between the size of the cyst and the patient's age but not on gender, location, type of cyst, and pathological fracture [23]. Another study conducted by Baig et al. showed the same thing that age was reported to be a reliable predictor, with children $>10$ years of age having a higher rate of cyst healing than those $<10$ years old [15]. Hashemi-Nejad and Cole said that there was no significant relationship between radiology results and cyst size, type or age [20]. Recently, Haidar et al. reported that a lesion located $<2 \mathrm{~cm}$ from the growth plate may be a risk factor for recurrence. In the present study, a significantly higher recurrence rate was found for patients with a lesion contacting the physis [16]. However, the other studies demonstrated that the results of PSI might be worse in as many as half of the patients had the lesion relapses [26]. In addition, despite its anti-inflammatory properties, extra care should be taken when administering steroid injection, due to its possible adverse effect [2730]. Palanisamy et al. showed that the number of adverse drug reaction of steroid was $2(3,3 \%)$ [31].

\section{CONCLUSION}

Steroid injection therapy for SBC yielded a good functional result. It gets solid union relatively quickly, have a simple operation procedure, is widely available, and have less side effect.Therefore, this procedure could be a choice for treatment of SBCs patient. To furthermore strengthen this conclusion, Further study needs to be conducted with more sample size.

\section{AUTHOR CONTRIBUTIONS}

AFK performed the operation, wrote the paper, and made a scientific analysis. A and YP performed the documentation of the patient and follow-up care and wrote the paper. 


\section{CONFLICT OF INTERESTS}

The authors declare that there is no conflict of interests regarding the publication of this paper.

\section{REFERENCES}

1. Ulici A, Balanescu R, Topor L, Barbu M. The modern treatment of the simple bone cysts. J Med Life 2012;5:469-73.

2. Sakamoto A, Matsuda S, Yoshida T, Iwamoto Y. Clinical outcome following surgical intervention for a solitary bone cyst: Emphasis on treatment by curettage and steroid injection. J Orthop Sci 2010;15:553- 9 .

3. Komiya S, Kawabata R, Zenmyo M, Hashimoto S, Inoue A. Increased concentrations of nitrate and nitrite in the cyst fluid suggesting increased nitric oxide synthesis in solitary bone cysts. J Orthop Res 2000; 18:281- 8 .

4. Gerasimov AM, Toporova SM, Furtseva LN, Berezhnoy AP, Vilensky EV, Alekseeva RI. The role of lysosomes in the pathogenesis of unicameral bone cysts. Clin Orthop Relat Res 1991;266:53-63.

5. Shindell R, Huurman WW, Lippiello L, Connolly JF. Prostaglandin levels in unicameral bone cysts treated by intralesional steroid injection. J Pediatr Orthop 1989;9:516-9.

6. Komiya S, Tsuzuki K, Mangham DC, Sugiyama M, Inoue A. Oxygen scavengers in simple bone cysts. Clin Orthop Relat Res 1994:308:199- 206.

7. Mirra JM, Bernard GW, Bullough PG, Johnston W, Mink G. Cementumlike bone production in solitary bone cysts. (so-called "cementoma" of long bones). Report of three cases. Electron microscopic observations supporting a synovial origin to the simple bone cyst. Clin Orthop Relat Res 1978;305:295-307.

8. Vayego SA, De Conti OJ, Varella-Garcia M. Complex cytogenetic rearrangement in a case of unicameral bone cyst. Cancer Genet Cytogenet 1996;86:46-9.

9. Flont P, Kolacinska-Flont M, Niedzielski K. Factors predictive of positive response to steroid therapy in simple bone cysts: An old trick that still works. Int Orthop 2013;37:1519-25.

10. Suei Y, Taguchi A, Nagasaki T, Tanimoto K. Radiographic findings and prognosis of simple bone cysts of the jaws. Dentomaxillofac Radiol 2010;39:65-71.

11. Scaglietti O, Marchetti PG, Bartolozzi P. The effects of methylprednisolone acetate in the treatment of bone cysts. Results of three years follow-up. J Bone Joint Surg (Br) 1979;61:200-4

12. Kadhim M, Thacker M, Kadhim A. Treatment of unicameral bone cyst: Systematic review and meta-analysis. J Child Orthop 2014;8:171-91.

13. Hagmann S, Eichhorn F, Moradi B, Gotterbarm T, Dreher T, Lehner B, et al. Mid-and long-term clinical results of surgical therapy in unicameral bone cysts. BMC Musculoskelet Disord 2011;12:281.

14. Mylle J, Burssens A, Fabry G. Simple bone cysts. Arch Orthop Trauma
Surg 1992;111:297-300

15. Baig R, Eady JL. Unicameral (simple) bone cysts. S Med J 2006;99:966 76

16. Haidar SG, Culliford DJ, Gent ED, Clark NM. Distance from the growth plate and its relation to the outcome of unicameral bone cyst treatment. J Child Orthop 2011;5:151-6.

17. Kao ST, Scott DD. A Review of bone substitutes. Oral Maxillofac Surg Clin N Am 2007;19:513-21.

18. Yandow S. What is the best treatment for simple bone cysts. In: Wright JG, editor. Evidence-Based Orthopaedics. $2^{\text {nd }}$ ed. Philadelphia, PA: Elsevier; 2009. p. 683-702.

19. Campanacci M, Capanna R, Picci P. Unicameral and aneurysmal bone cysts. Clin Orthop Relat Res 1986;204:25-36

20. Hashemi-Nejad A, Cole WG. Incomplete healing of simple bone cysts after steroid injections. J Bone Joint Surg 1997;79-B:5.

21. Cho Hs, Oh JH, Kim Hs, Kang Hg, Lee SH. Unicameral bone cysts a comparison of injection of steroid and grafting with autologous bone marrow. J Bone Joint Surg Br 2007;89-B:222-6.

22. Pavone V, Caff G, Di Silvestri C, Avondo S, Sessa G. Steroid injections in the treatment of humeral unicameral bone cysts: Long-term follow-up and review of the literature. Eur J Orthop Surg Traumatol 2014;24:497- 503

23. Chang C, Stanton R, Glutting J. Unicameral bone cyst treated by injection of bone marrow or methylprednisolone. J Bone Joint Surg 2002;84:407-12.

24. Oppenheim WL, Galleno H. Operative treatment versus steroid injection in the management of unicameral bone cysts. J Pediatr Orthop 1984;4:1-7.

25. Faisham W, Nawasz AH, Ezane AW, Zulmi W, Ibrahim W, Halim AR. Non-Operative treatment versus steroid injections in the management of unicameral bone cysts. Malays Orthop J 2011;5:2 .

26. Shirai T, Tsuchiya H, Terauchi R, Tsuchida S, Mizoshiri N, Ikoma K. Treatment of a simple bone cyst using a cannulated hydroxyapatite pin. Medicine 2015;94:25.

27. Corrêa GM, Abreu VG, De Abreu Martins DA, Takahashi JA, Fontoura HD, Cara DC, et al. Anti-inflammatory and antimicrobial activities of steroids and triterpenes isolated from aerial parts of Justicia acuminatissima (Acanthaceae). Int J Pharm Pharm Sci 2014;6:75-81.

28. Pratik M. Formulation, development, and evaluation of ethosomal drug delivery for terbinafine hydrochloride. Int J Pharm Adv Pharm 2014:4:200-6.

29. Sivakumar NR. Steroids in root canal treatment. Int J Pharm Pharm Sci 2014;6:17-9

30. Umamaheswari A, Bhuvaneswari K, Ramalingam S. Steroid-induced anaphylaxis. Asiann J Pharm Clin Res 2017;10:1-2.

31. Palanisamy S, Sg K, Kumaran A, Rajasekaran A. A study on assessment, monitoring and reporting of adverse drug reactions in indian hospital. Asiann J of Pharm Clin Res 2011;4:2-3. 


\section{APPENDIX}

Consent Form for Case Reports

Case Report: Simple Bone Cyst Treated with Percutaneous Steroid Injection

\section{Principal Investigator: Achmad Fauzi Kamal}

Department of Orthopaedic and Traumatology, Cipto Mangunkusumo General Hospital/Faculty of Medicine University of Indonesia (+62) 81511450189

You are being asked to consider allowing Achmad Fauzi Kamal to use information about your disease to write what is called a case report. Case reports are typically used to share new unique information experienced by one patient during his/her clinical care that may be useful for other physicians and members of a healthcare team. A case report may be published (in print and/or via internet dissemination) for others to read and/or presented at a conference. This form explains the purpose of this case report. Please read this form carefully and take your time to make your decision and ask any questions that you may have.

The purpose of this case report is to inform other physicians about the effectiveness of methylprednisolone injections to treat SBC.

Your information being used for this case report includes your selfidentity and medical history.

Achmad Fauzi Kamal is obligated to protect your privacy and not disclose your personal information (information about you and your health that identifies you as an individual,for example, name, date of birth, and medical record number). When the case report is published or presented, your identity will not be disclosed.

Although your personal information collected or obtained will be kept confidential and protected to the fullest extent of the law, there is a limited risk associated with this case report that could result in a loss of confidentiality by virtue of your unique experience.

You will not directly benefit from participating in this case report. The information that can be shared with other healthcare professionals, however, may improve the care that is received by others in the future.

Allowing your information to be used in this case report will not involve any additional costs to you. You will not receive any compensation.

Taking part in this case report is your choice (voluntary). You may choose not to take part or you may change your mind at any time.
However, once the case report is written and published, it will not be possible for you to withdraw it. Your decision will not result in any penalty or loss of benefits to which you are entitled including the quality of care you receive.

You will be told about any new information relating to this case report that may affect you.

Your signature below means that you have read the above information about this case report and have had a chance to ask questions to help you understand how your information will be used and that you give permission to allow your information to be used in this case report.

If you have any questions please contact Achmad Fauzi Kamal.

\section{SUBJECT CONSENT TO PARTICIPATE}

Case Report Title:

Name of Participant:

Participant/Substitute decision-maker

By signing this form, I confirm that:

- $\quad$ The case report has been fully explained to me and all of my questions have been answered to my satisfaction

- I have been informed of the risks and benefits, if any, of allowing my information to be used in this case report

- I have been informed that I do not have to participate in this case report

- I have read each page of this form

- I authorize access to my personal health information (medical record) as explained in this form

I have agreed to participate in this case report

Name of Participant/Substitute Signature Date

Decision-maker (print) 